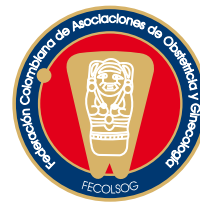

\title{
EDITORIAL
}

\section{MÁS CERCA DE SCIELO}

Carlos A. Agudelo, M.D., MSc.*

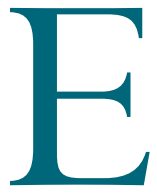
s bien sabido que en el concierto mundial, los países de América Latina representan solo una pequeña parte de los investigadores y la inversión en ciencia y tecnología. Colombia, a su vez, representa en América Latina una parte aún más pequeña en estos mismos aspectos. América Latina y Colombia en particular no están bien representadas en el material publicado por las revistas científicas indexadas, de acuerdo con el potencial que tienen y lo que producen. Así, por ejemplo, la revista British Medical Journal (http://bmj.bmjjournals.com/advice/ms_breakdown.shtml) informa que recibió 5.751 artículos para publicación en el año 2000 y aceptó sólo el 12 \% de los mismos. De América Central y del Sur se recibieron 27 artículos de los cuales fueron aceptados 2. Ninguno de estos provino de Colombia, que muestra una enorme debilidad aún frente a vecinos cuyo gasto en ciencia y tecnología es, en algunos casos, inferior. De lo anterior se deriva una consecuencia: América Latina y Colombia están mal representadas en los index internacionales.

El surgimiento de SciELO-Scientific Electronic Library Online (www.scielo.org) y su consolidación contribuirá a cambiar progresivamente este panorama. SciELO es un modelo para la publicación electrónica cooperativa de revistas científicas en Internet, para responder a las necesidades de la comunicación científica en los países en desarrollo y particularmente de América Latina y el Caribe. SciELO está conformado por un

* Coordinador Ejecutivo Comité Consultivo Nacional - SciELO Colombia conjunto de colecciones temáticas y regionales, a las cuales se suma ahora la colección de revistas colombianas.

Esfuerzos de muchos por muchos años, han permitido poner en funcionamiento el sitio SciELO Colombia (www.scielo.org.co). Se ha conformado un Comité Consultivo Nacional y en su primera fase de funcionamiento podrán incorporarse a SciELO las revistas nacionales que hacen parte de Publindex en las categorías A y B. Este proceso debe entenderse como una oportunidad para mejorar localmente la calidad de las revistas científicas, siguiendo criterios validados internacionalmente. Esta oportunidad permitirá consolidar el proceso previo de incremento en el número de revistas científicas y de mejoramiento de la calidad de las mismas. Esperamos que en pocos meses todas las revistas colombianas bien clasificadas en Publindex hayan logrado poner en práctica los planes de mejoramiento que les permitan incorporarse a SciELO Colombia. En este sentido, es claro que una mayor capacidad de comunicación científica, nacional e internacional, así como el impacto que logre SciELO Colombia en el posicionamiento internacional del país, dependerán en gran parte del esfuerzo que realicen las propias revistas y las instituciones que están a cargo de las mismas. Esto, sin embargo, no es suficiente para lograr todos los potenciales desarrollos en la comunicación científica de las revistas nacionales. Es también necesario contar con una política pública de apoyo a las revistas y a los procesos de transformación que están llevándose a cabo. 